\title{
Matrine inhibits the invasive and migratory properties of human hepatocellular carcinoma by regulating epithelial-mesenchymal transition
}

\author{
YUWEN WANG ${ }^{1,2 *}$, SHUJUN ZHANG ${ }^{3 *}$, JIA LIU $^{2}$, BIAOBIAO FANG ${ }^{2}$, JIE YAO $^{2}$ and BINGLIN CHENG ${ }^{2}$ \\ ${ }^{1}$ Shenzhen Longhua District Central Hospital, Shenzhen, Guangdong 518110; ${ }^{2}$ Department of Traditional Chinese Medicine, \\ The First Affiliated Hospital of Harbin Medical University, Harbin, Heilongjiang 150000; ${ }^{3}$ Department of Pathology, \\ The Fourth Affiliated Hospital of Harbin Medical University, Harbin, Heilongjiang 150001, P.R. China
}

Received February 25, 2017; Accepted April 13, 2018

DOI: $10.3892 / \mathrm{mmr} .2018 .9023$

\begin{abstract}
Matrine has been reported to be an effective anti-tumor therapy; however, the anti-metastatic effects of matrine on hepatocellular carcinoma (HCC) and the molecular mechanism(s) involved remain unclear. Therefore, the aims of the present study were to evaluate the effects of matrine on hepatoma and to determine the associated mechanism(s) involved. In the present study, matrine was confirmed to prevent the proliferation of HCC cells and it was observed that matrine also inhibited the migratory, and invasive capabilities of HCC at non-toxic concentrations. Additionally, matrine increased epithelial-cadherin expression and decreased the expression levels of vimentin, matrix metalloproteinase (MMP)2, MMP9, zinc finger protein SNAI1 and zinc finger protein SNAI2. These results indicate that the anti-metastatic effect of matrine may be associated with epithelial-mesenchymal transition (EMT). Furthermore, matrine can increase phosphatidylinositol 3,4,5-trisphosphate 3-phosphatase and dual-specificity protein phosphatase PTEN (PTEN) expression and reduce phosphorylated-protein kinase B (Akt) levels. In conclusion, these results suggested that matrine is a potential therapeutic agent that can suppress cancer-associated invasion and migration via PTEN/Akt-dependent inhibition of EMT.
\end{abstract}

Correspondence to: Dr Binglin Cheng, Department of Traditional Chinese Medicine, The First Affiliated Hospital of Harbin Medical University, 122 Youzheng Street, Nangang, Harbin, Heilongjiang 150000, P.R. China

E-mail: chengbinglin1971@126.com

*Contributed equally

Key words: matrine, hepatocellular carcinoma, migration, invasion, epithelial-to-mesenchymal transition, PTEN, AKT

\section{Introduction}

Hepatocellular carcinoma (HCC) is the most frequently occurring primary cancer of the liver and is the 5th, and the 3rd leading cause of cancer-associated death worldwide among women and men, respectively (1). These poor outcomes result from its high recurrence following liver resection and its resistance to systemic chemotherapy $(2,3)$. As cases of HCC are frequently identified at advanced stages of the disease, these patients are only eligible for palliative care. Furthermore, as no effective palliative chemotherapies are available, the prognosis of patients with advanced HCC is poor (4). Therefore, developing pharmacologically effective agents from natural products with minimal toxicity or minimal adverse effects has become an area of interest.

Epithelial-mesenchymal transition (EMT), the process by which epithelial cancer cells lose their polarity and become motile mesenchymal cells, has been implicated in carcinoma invasion and metastasis (5). Downregulation of epithelial (E)-cadherin and the acquisition of mesenchymal markers including vimentin, are regarded as the key steps of EMT. The zinc-finger proteins Snai1 (Snail) and Snai2 (Slug) are the most prominent suppressors of E-cadherin transcription $(6,7)$. Matrix metalloproteinases (MMPs) are a family of metalloendopeptidase that cleave the protein components of the extracellular matrix (ECM) and the endothelial cell basement membrane (8). MMPs serve a central role in tumor EMT by the cleavage of components of the ECM and the endothelial cell basement membrane. MMP2 and MMP9, members of the MMP family, have been demonstrated in cancer tissues, and are associated with the processes of tumor aggression, and metastasis in human cancer (9). Furthermore, a previous study reported that MMP2 and MMP9 could break down cell surface associated molecules (10), and could cleave the E-cadherin ectodomain near the plasma membrane into soluble E-cadherin (11), which may be involved in MMPs-enhanced invasion and metastatic potential of cancer cells.

Matrine is an essential compound identified in the traditional Chinese herb Sophora flavescens Ait. (12), which has been used to treat viral hepatitis, liver cirrhosis, cardiac arrhythmia and skin inflammations in China for centuries; furthermore, 
this herb does not exhibit any obvious side-effects (13). Previously findings revealed that matrine exerts anti-tumor effects on several tumor cell types, including HCC, as well as pancreatic, gastric and breast cancer. In addition, matrine was demonstrated to enhance the immune function of patients and therefore improve the quality of life of patients (14). Although matrine has been used clinically to treat various types of cancer in recent years, the therapeutic efficacy of matrine for EMT of HCC remains poorly understood.

Consistent with the published literature, the present study aimed to ascertain whether there were any alterations in EMT in hepatoma cells as a result of being treated with matrine, to investigate the mechanisms underlying the diminished EMT activity of matrine through the phosphatidylinositol 3,4,5-trisphosphate 3-phosphatase and dual-specificity protein phosphatase PTEN (PTEN)/protein kinase B (Akt) signaling pathway and altered the expression of proteins involved in EMT, including MMP2, MMP9, E-cadherin, vimentin, Slug and Snail. The aim of the present study was to develop novel strategies for the treatment of HCC.

\section{Materials and methods}

Chemicals and reagents. Matrine (purity >98\%), MTT, Triton X-100 and dimethyl sulfoxide (DMSO) were all purchased from Sigma-Aldrich (Merck KGaA, Darmstadt, Germany). Anti-phosphorylated (p)-Akt (cat. no. 66444-1-1g), anti-Akt (cat. no. 55230-1-AP), anti-PTEN (cat. no. 22034-1-AP), anti-E-cadherin (cat. no. 20874-1-AP) and anti-vimentin (cat. no. 10366-1-AP) antibodies were all purchased from Wuhan Sanying Biotechnology (Wuhan, China). Anti-MMP2 (cat. no. 40994), anti-MMP9 (cat. no. 3852), anti-Snail (cat. no. 3879), anti-Slug (cat. no. 9585) antibodies and DyLight ${ }^{\mathrm{TM}} 594$ Phalloidin (cat. no. 12877) were all purchased from Cell Signaling Technology, Inc. (Danvers, MA, USA). The anti- $\beta$-actin (cat. no. TA-09) antibody was purchased from OriGene Technologies, Inc. (Beijing, China). Radio immunoprecipitation assay (RIPA) lysis buffer and DAPI staining solution were purchased from the Beyotime Institute of Biotechnology (Shanghai, China).

Cell culture. Fetal bovine serum (FBS), penicillin/streptomycin and trypsin were all purchased from Gibco (Thermo Fisher Scientific, Inc., Waltham, MA, USA). Dulbecco's modified Eagle's medium (DMEM) was purchased from Invitrogen (Thermo Fisher Scientific, Inc.). The human hepatoma cell line Huh-7 was purchased from the Shanghai Institute of Biochemistry and Cell Biology, Chinese Academy of Science (Shanghai, China). Huh-7 cells were cultured in DMEM supplemented with $100 \mathrm{U} / \mathrm{ml}$ penicillin, $100 \mu \mathrm{g} / \mathrm{ml}$ streptomycin and $10 \% \mathrm{FBS}$ and incubated at $37^{\circ} \mathrm{C}$ in a humidified atmosphere containing $5 \% \mathrm{CO}_{2}$.

Cell viability assays. The MTT assay was used to assess the cytotoxic activity of matrine. Huh-7 cells were plated in 96-well culture plates $\left(1 \times 10^{4}\right.$ cells/well) and allowed to adhere overnight at room temperature, following which the cells were treated with various concentrations of matrine $(0,0.2,0.4,0.8,1.0,1.2,1.4,1.6,1.8$, or $2.0 \mathrm{mg} / \mathrm{ml})$. The cells were subsequently incubated for 24 and $48 \mathrm{~h}$ then they were washed twice with PBS and treated with $5 \mathrm{mg} / \mathrm{ml}$ MTT for $4 \mathrm{~h}$. The cells were washed with PBS and then solubilized with $150 \mu \mathrm{l}$ DMSO. The optical density values were measured at an absorbance of $490 \mathrm{~nm}$ using a Wellscan reader (Thermo Labsystems, Santa Rosa, CA, USA). The percentage inhibition of cellular proliferation was calculated using equation 'the inhibitory percentage (\%) = [1 - A490(test)/A490(blank)] $\mathrm{x} 100 \%$. The assays were performed in triplicate in three independent experiments.

Colony forming assay. Huh-7 cells in the exponential growth phase were seeded into 6-well plates at a density of $8 \times 10^{2}$ cells/well. Following incubation of the cells for $12 \mathrm{~h}$, they were treated with $0,0.8$, or $1.6 \mathrm{mg} / \mathrm{ml}$ matrine for $24 \mathrm{~h}$ and then continuously cultured in fresh medium at $37^{\circ} \mathrm{C}$ in a humidified atmosphere containing $5 \% \mathrm{CO}_{2}$. Following 10-15 days of culture, the cells were first washed twice with PBS, then fixed with methanol for $30 \mathrm{~min}$ at room temperature and finally stained with $0.5 \%$ crystal violet for $30 \mathrm{~min}$ at room temperature. A colony was defined as a unit of at least 50 cells and all visible colonies were counted by light microscopy. The colony formation rate was reported as a percentage and calculated as the number of colonies/the number of seeded cells $\mathrm{x} 100$. The assays were performed in triplicate in three independent experiments.

Wound healing assays. For the wound healing assays, Huh-7 cells were seeded in 6-well plates at a density of $2 \times 10^{5}$ cells/well and cultured for $24 \mathrm{~h}$. Wounds were scratched with a $10 \mathrm{ml}$ pipette tip and then PBS was used to wash the wells and remove floating cells prior to the addition of serum-free medium. The cells were then treated with $0,0.2,0.4$ or $0.8 \mathrm{mg} / \mathrm{ml}$ matrine for 0,12 and $24 \mathrm{~h}$. The migratory distance of the cells was measured and analyzed using ImageJ 1.48 version (National Institutes of Health, Bethesda, MD, USA). The tests were performed in triplicate in three independent experiments.

In vitro invasion and migration assays. Cell migration and invasion assays were performed using Transwell chambers with $8-\mu \mathrm{m}$ pores (Corning, Incorporated, Corning, NY, USA). Huh-7 cells were pretreated with $0,0.2,0.4$ or $0.8 \mathrm{mg} / \mathrm{ml}$ matrine for $24 \mathrm{~h}$. For the migration assay, $1 \times 10^{4}$ cells/well in serum-free medium were seeded in the upper chamber on a non-coated membrane. The lower chamber was filled with medium containing 20\% FBS, whereas the upper chamber with a membrane pre-coated with Matrigel (BD Biosciences, Franklin Lakes, NJ, USA) were used for the invasion assay. The cells were subsequently incubated for $24 \mathrm{~h}$ at $37^{\circ} \mathrm{C}$, those on the upper side of the inserts were removed by swabbing with a cotton swab and the cells on the bottom side of the filter were fixed with $100 \%$ methanol for $30 \mathrm{~min}$ at room temperature and stained with $0.5 \%$ crystal violet for $30 \mathrm{~min}$ at room temperature. The cells on the lower surface were then counted and images were captured under an inverted light microscope (Olympus Corporation, Tokyo, Japan). The assays were performed in triplicate in three independent experiments.

Immunofluorescence. Huh-7 cells were plated onto chamber slides at $2 \times 10^{4}$ cells per chamber for $12 \mathrm{~h}$ and stimulated with 0 and $0.8 \mathrm{mg} / \mathrm{ml}$ matrine for $24 \mathrm{~h}$. Then, the cells were fixed 
with $4 \%$ paraformaldehyde for $30 \mathrm{~min}$ at room temperature and subsequently permeabilized with $0.25 \%$ Triton $\mathrm{X}-100$ for $20 \mathrm{~min}$ at room temperature. The slides were then treated with $0.5 \%$ bovine serum albumin (BSA; Beyotime Institute of Biotechnology, Jiangsu, China) in $0.1 \%$ Tween-20 for $30 \mathrm{~min}$ at room temperature, primary antibodies targeting E-cadherin and vimentin were added at a 1:1,000 dilution and incubated on the slides overnight at $4^{\circ} \mathrm{C}$. Secondary antibodies conjugated with the green fluorescent Alexa Fluor 594 dye (FITC Conjugated Goat Anti-Rabbit IgG; cat. no. TA130021), were purchased from OriGene Technologies, Inc. (Rockville, MD, USA), were added to the slides at a dilution of 1:1,000 for $1 \mathrm{~h}$ at room temperature. Then, the cells were washed with PBS and the coverslips were mounted using an anti-fade mounting solution containing DAPI prior to imaging the cells for $10 \mathrm{~min}$ at room temperature. The projected cell area was evaluated using Image J software. The assays were performed in triplicate in three independent experiments.

Western blot analysis. Huh-7 cells were planted in 6-well plates at $2 \times 10^{5}$ cells per well, treated with different concentrations of matrine $(0,0.2,0.4$, or $0.8 \mathrm{mg} / \mathrm{ml})$ for $36 \mathrm{~h}$ and then lysed using a RIPA buffer. The lysates were centrifuged at $4{ }^{\circ} \mathrm{C}$ at $12,000 \mathrm{x} \mathrm{g}$ for $15 \mathrm{~min}$ and the protein concentration of the remaining supernatants was measured using a bicinchoninic protein assay kit (Beyotime Institute of Biotechnology). Samples of total protein $(20 \mu \mathrm{g})$ were separated using 12\% SDS-PAGE. The separated proteins were then transferred to polyvinylidene difluoride membranes (EMD Millipore, Billerica, MA, USA) at $0.8 \mathrm{~mA} / \mathrm{cm}^{2}$ for $2 \mathrm{~h}$. Following blocking of these membranes with a solution of $5 \%$ non-fat dry milk in buffer at $37^{\circ} \mathrm{C}$ for $1 \mathrm{~h}$, they were treated with antibodies targeting E-cadherin, vimentin, Slug, Snail, PTEN, Akt, p-Akt and $\beta$-actin (all dilutions $1: 1,000)$ overnight at $4^{\circ} \mathrm{C}$. Then, the membranes were washed and incubated with horseradish peroxidase-conjugated $(1: 1,000)$ anti-mouse (cat. no. ZB-5305) or $(1: 1,000)$ anti-rabbit antibodies (cat. no. ZB-5301; Beijing Zhongshan Golden Bridge Biotechnology Co., Ltd., Beijing, China) at room temperature for $1 \mathrm{~h}$. The protein bands on the membranes were visualized using ECL detection reagents (P0018, BeyoECL Plus; Beyotime Biotechnology, Jiangsu, China). In addition, the antibodies targeting MMP2 and MMP9 (all dilutions 1:1,000) when the cells were treated with matrine $(0,0.4$ and $0.8 \mathrm{mg} / \mathrm{ml})$ were tested as described above. ImageJ software was used to perform the densitometric analyses. The experiments were performed in triplicate in three independent experiments.

Actin staining of the cytoskeleton. Huh-7 cells, which were treated with matrine $(0,0.8 \mathrm{mg} / \mathrm{ml})$ were grown on coverslips and fixed with $4 \%$ fresh paraformaldehyde for $10 \mathrm{~min}$ at room temperature, permeabilized with $0.1 \%$ Triton X-100 in PBS for $20 \mathrm{~min}$ at room temperature, and then blocked with $5 \%$ BSA at room temperature for $1 \mathrm{~h}$. Subsequently, the cells were stained with Phalloidin for $2 \mathrm{~h}$ at room temperature in the dark. Following being washed, the cells were counterstained with DAPI for $10 \mathrm{~min}$ at room temperature. A fluorescence microscope (Eclipse 90i; Nikon Corporation, Tokyo, Japan) was employed to observe the distribution of filamentous (F)-actin. The assays were performed in triplicate in three independent experiments.

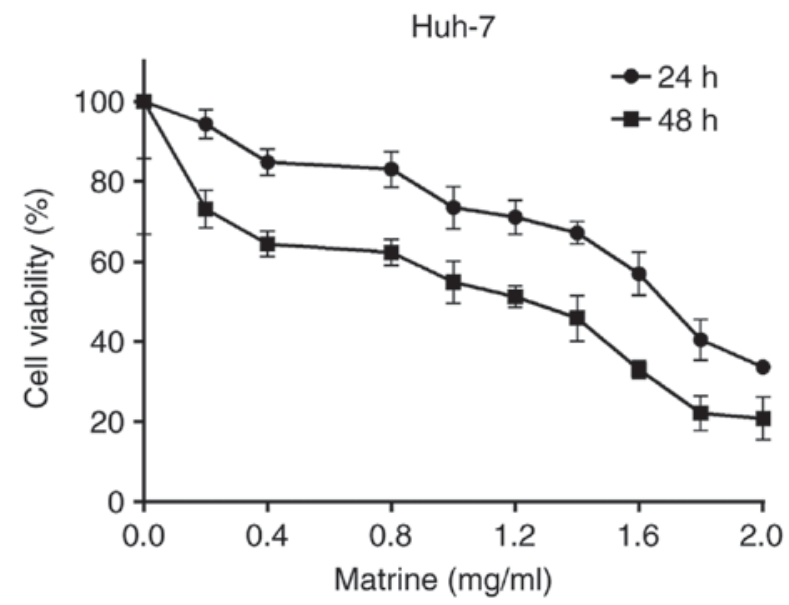

Figure 1. MTT assay demonstrating the cytotoxicity of matrine in hepatocellular carcinoma cells. Huh-7 cells were treated with matrine at concentrations of $0,0.2,0.4,0.8,1.0,1.2,1.4,1.6,1.8$ and $2.0 \mathrm{mg} / \mathrm{ml}$ for 24 and $48 \mathrm{~h}$. Matrine repressed the growth of Huh-7 cells in a dose- and time-dependent manner. The data are presented as the mean \pm standard deviation of three independent experiments.

Statistical analysis. Statistical analyses were performed using either the Statistical Program for Social Sciences (SPSS) version 17.0 (SPSS, Inc., Chicago, IL, USA) or the GraphPad Prism software package (v. 4.02; Graphpad, Inc., San Diego, CA, USA). Each experiment was repeated at least three times. The values are expressed as the mean \pm standard deviation. Either the Student's t-test or one-way analysis of variance followed by the Newman-Keuls method were performed to analyze the difference between two groups and multiple groups, respectively. $\mathrm{P}<0.05$ was considered to indicate a statistically significant difference.

\section{Results}

Matrine inhibits the cell viability of the human hepatoma cell line Huh-7. The effect of various concentrations of matrine ( 0 to $2 \mathrm{mg} / \mathrm{ml}$ ) on the cell viability of Huh-7 cells following exposure for 24 or $48 \mathrm{~h}$ is demonstrated in Fig. 1. At $1 \mathrm{mg} / \mathrm{ml}$, matrine inhibited the cell viability of Huh-7 cells, whereas at concentrations lower than $1 \mathrm{mg} / \mathrm{ml}$, the inhibitory effect was not marked following $24 \mathrm{~h}$. Therefore, concentrations lower than $1 \mathrm{mg} / \mathrm{ml}$ were selected for the experiments associated with invasion and metastasis.

To investigate the long-term effects of matrine on Huh-7 cells proliferation, a colony formation assay was performed. Cells subjected to long-term matrine exposure exhibited significantly reduced colony-forming abilities ( $\mathrm{P}<0.01$; Fig. 2). Furthermore, this suppression was more significant in cells exposed to higher concentrations of matrine $(\mathrm{P}<0.001)$. These results indicated that a matrine concentration $>1 \mathrm{mg} / \mathrm{ml}$ exerts a suppressive effect on the proliferative abilities of Huh-7 cells.

Matrine inhibits the migration and invasion of Huh-7 cells. In the present study, the migratory ability of cells treated with matrine was significantly decreased compared with the control Huh-7 cells $(\mathrm{P}<0.05$; Figs. 3 and 4$)$. The results demonstrated that matrine inhibited the invasion and migration of Huh-7 cells in a concentration-dependent manner. In the wound 
A

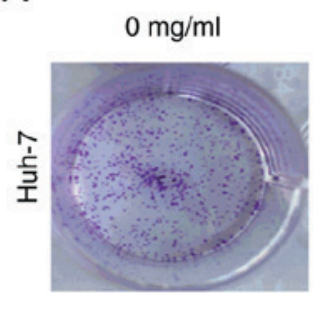

$0.8 \mathrm{mg} / \mathrm{ml}$

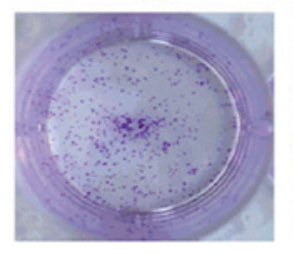

$1.6 \mathrm{mg} / \mathrm{ml}$

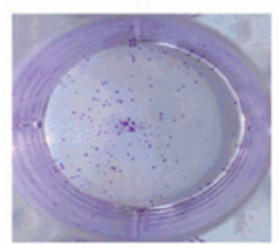

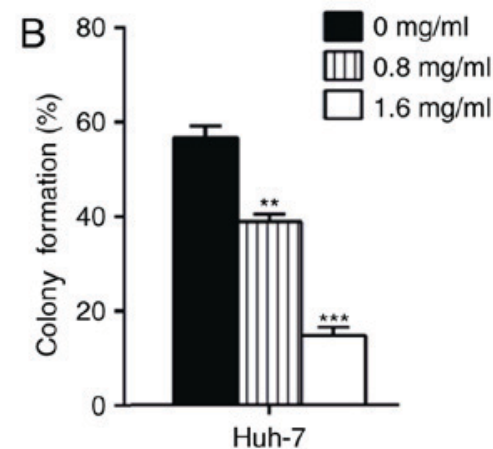

Figure 2. Suppressive effect of matrine on colony formation in Huh-7 cells. (A) Representative images of the colony formation assay. (B) Analysis of colony formation rates of Huh-7 cells. The data are presented as the mean \pm standard deviation of three independent experiments. ${ }^{* *} \mathrm{P}<0.01$ vs. and ${ }^{* * *} \mathrm{P}<0.001$ vs. the $0 \mathrm{mg} / \mathrm{ml}$ matrine group.

A

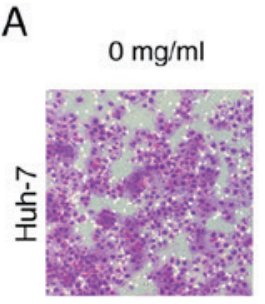

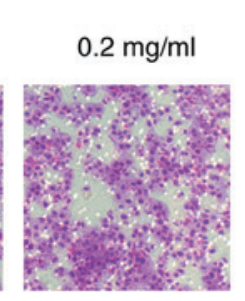

$0.4 \mathrm{mg} / \mathrm{ml}$

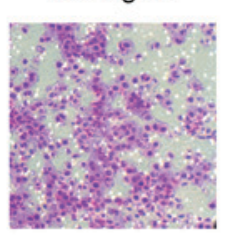

B

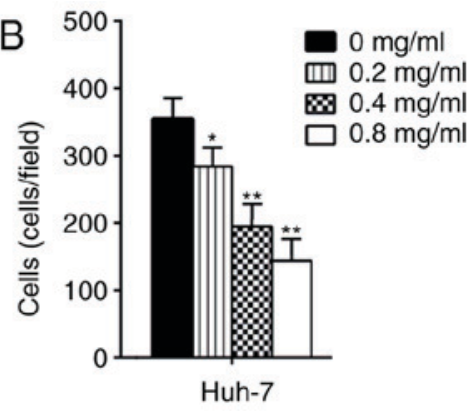

Figure 3. Suppressive effect of matrine on the migration of Huh-7 cells. (A) Representative images of the migration assay (magnification, x100). (B) Analysis of the migration of Huh-7 cells. The data are presented as the mean \pm standard deviation of three independent experiments. ${ }^{*} \mathrm{P}<0.05$ and ${ }^{* *} \mathrm{P}<0.01$ vs. the group of matrine with $0 \mathrm{mg} / \mathrm{ml}$.

A

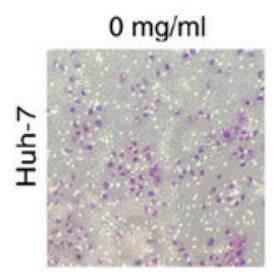

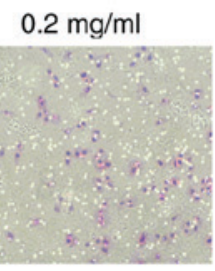

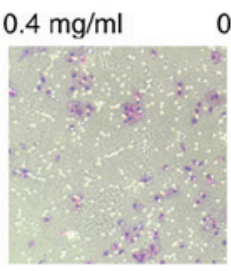

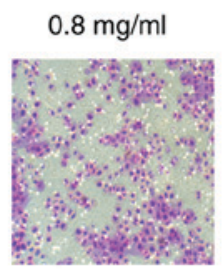

Figure 4. The suppressive effect of matrine on invasion in Huh-7 cells. (A) Representative images of the invasion assay (magnification, x100); (B) Analysis of the invasion of Huh-7 cells. The data are presented as the mean \pm standard deviation of three independent experiments. ${ }^{*}<0.05$ and ${ }^{* *} \mathrm{P}<0.01 \mathrm{vs}$. the $0 \mathrm{mg} / \mathrm{ml}$ matrine group.

healing assays, the migration area (\%) in the matrine group was significantly increased compared with the control group $(\mathrm{P}<0.05$; Fig. 5). These experiments illustrated that matrine may serve an essential role in regulating the migratory and invasive abilities of a HCC cell line.

Matrine inhibits EMT by suppressing vimentin and enhancing E-cadherin expression in human Huh-7 HCC cells. Vimentin and E-cadherin have been reported to serve important roles in EMT (15). To determine how matrine induces EMT in Huh-7 cells, Huh-7 cells were stimulated with $0.8 \mathrm{mg} / \mathrm{ml}$ matrine for $24 \mathrm{~h}$ (Fig. 6) and immunofluorescence was used to measure the levels of vimentin and E-cadherin expressed in these cells. It was observed that matrine induced the downregulation of vimentin expression and the upregulation of E-cadherin expression; these results indicate that matrine serves a critical role in reducing EMT by decreasing vimentin expression and increasing E-cadherin expression.

Matrine represses the cancer cells exhibiting an EMT-like phenotypic alteration. Previous studies highlighted EMT as the mechanism by which differentiated epithelial cells undergo notable morphological alterations and acquire more motile and invasive capabilities (16-19). Cytoskeletal reorganization is also a characteristic of EMT and this feature was observed by F-actin staining. As demonstrated in Fig 7A, the stress fibers in Huh-7 cells appeared as lamellipodia and extensive parallel bundles, which were densely stained and exhibited 

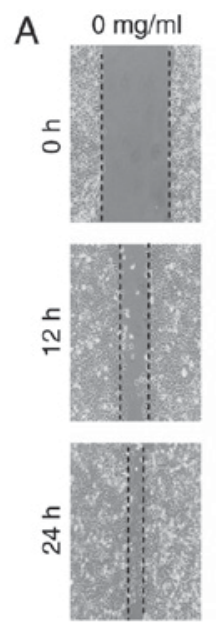
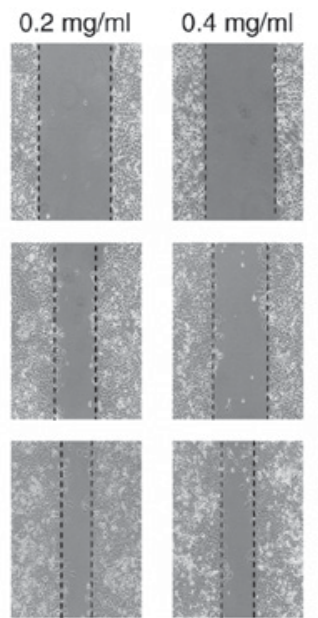

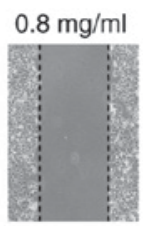

B

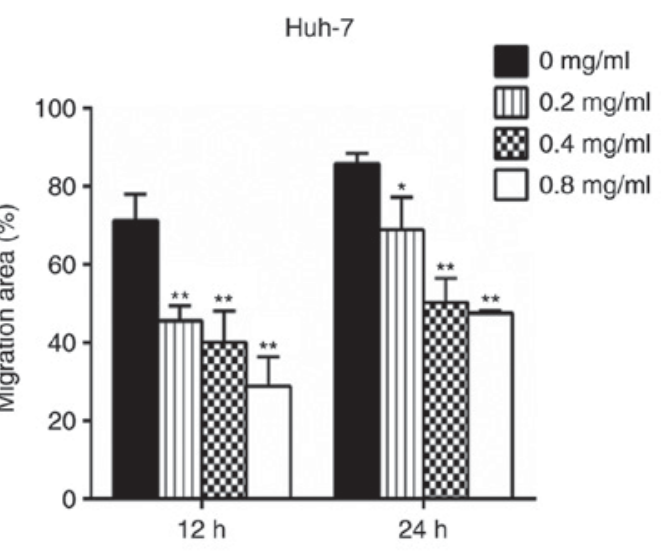

Figure 5. Effect of matrine on the mobility of Huh-7 cells. (A) Representative images of the wound healing assays at 0,12 and 48 h (magnification, $\mathrm{x} 100$ ). (B) Analysis of the migration area of Huh-7 cells. The data are presented as the mean \pm standard deviation of three independent experiments. $\mathrm{P}<0.05$, and ${ }^{* * *} \mathrm{P}<0.01$ vs. the $0 \mathrm{mg} / \mathrm{ml}$ matrine group.
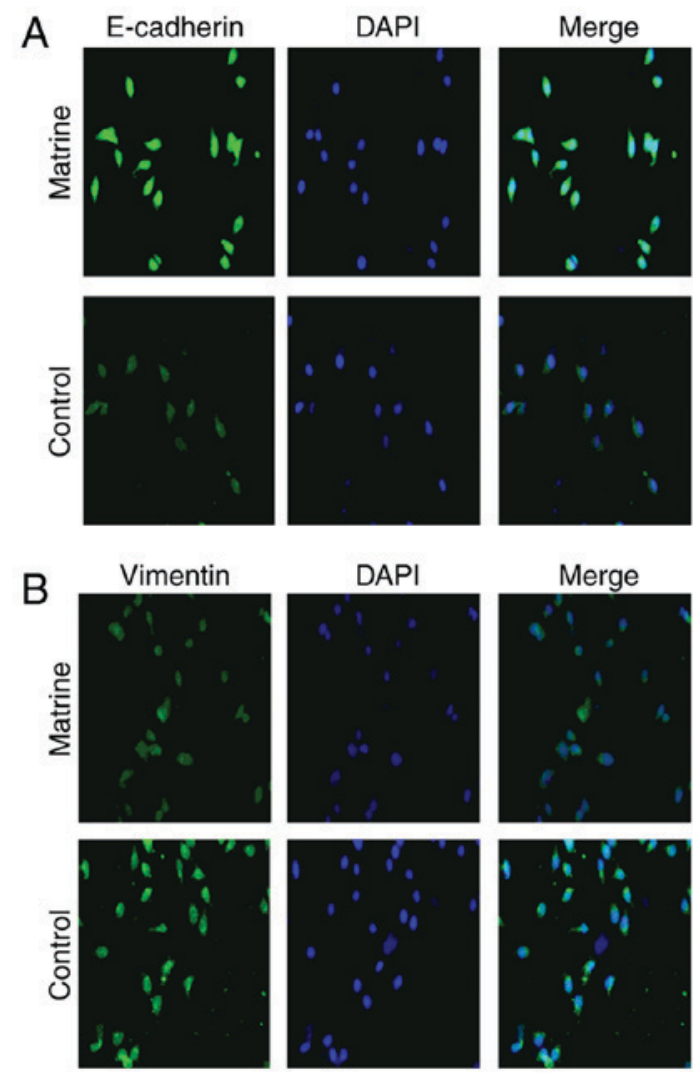

Figure 6. Effect of matrine on E-cadherin and vimentin expression in Huh-7 cells. Representative single-color and merged images of Huh-7 cells illustrate the immunofluorescence staining for (A) E-cadherin (green) and (B) vimentin (green), with the cell nucleus (blue) stained using DAPI (magnification, x100). E, epithelial.

well-organized structures. In contrast, the lamellipodia disappeared and the parallel bundles were disrupted in the cells treated with matrine, which also demonstrated loosely organized F-actin (Fig. 7B).

Matrine suppresses the expression of Akt/p-Akt, vimentin, MMP2, MMP9, Slug and Snail and increases the expression
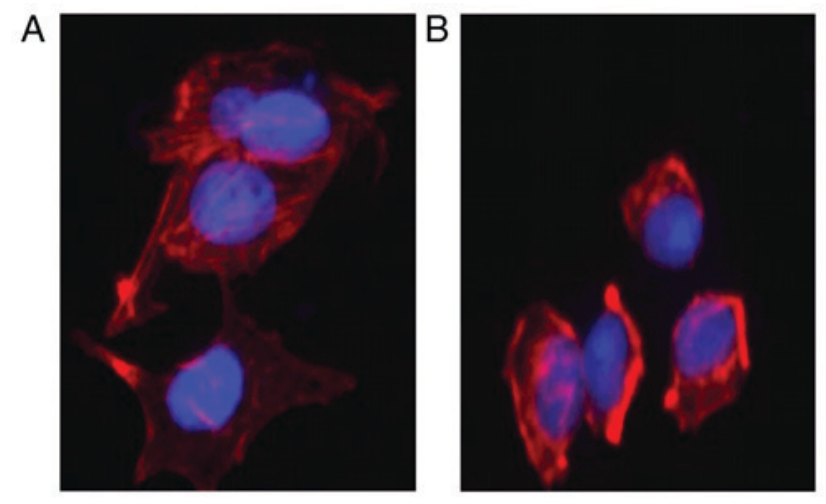

Figure 7.Effect of matrine on the cytoskeleton in Huh-7 cells. (A) Representative phalloidin staining to observe the actin cytoskeleton in Huh-7 cells, with the cell nucleus (blue) stained using DAPI (magnification, x100). (B) Representative phalloidin staining to observe the actin cytoskeleton in Huh-7 cells which were treated with $0.8 \mathrm{mg} / \mathrm{ml}$ matrine, with the cell nucleus (blue) stained using DAPI (magnification, x100).

of PTEN and E-cadherin. Huh-7 cells treated with matrine for $24 \mathrm{~h}$ were subjected to a western blotting assay to determine the expression levels of vimentin, MMP2, MMP9, Slug, Snail and E-cadherin. Figs. 8 and 9 revealed that compared with control Huh-7 cells, matrine-treated cells demonstrated significantly increased E-cadherin protein levels $(\mathrm{P}<0.01)$ and reduced expression of vimentin, MMP2, MMP9, Slug and Snail in a concentration-dependent manner. The effect of matrine on PTEN and p-Akt expression in Huh-7 cells, was also investigated and the western blot analysis demonstrated that matrine significantly increased PTEN expression and significantly reduced the levels of $\mathrm{p}$-Akt in a concentration-dependent manner $(\mathrm{P}<0.05$; Fig. 10).

\section{Discussion}

HCC is the most common liver malignancy and a major health problem worldwide. Surgical resection and liver transplantation, which are the current gold standards for the treatment of HCC, are less than satisfactory due to metastasis and high recurrence 
A

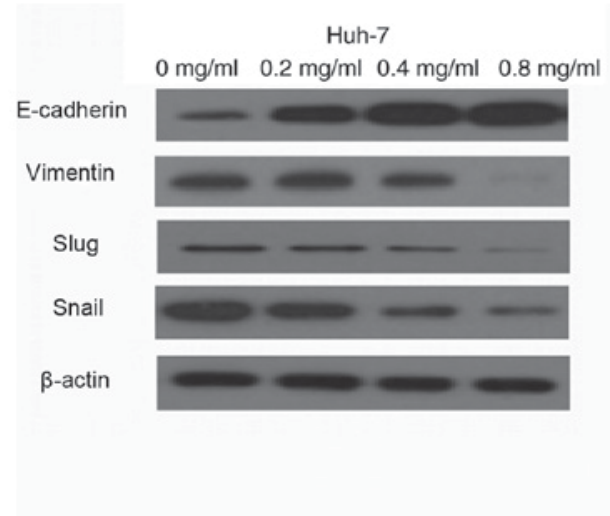

B

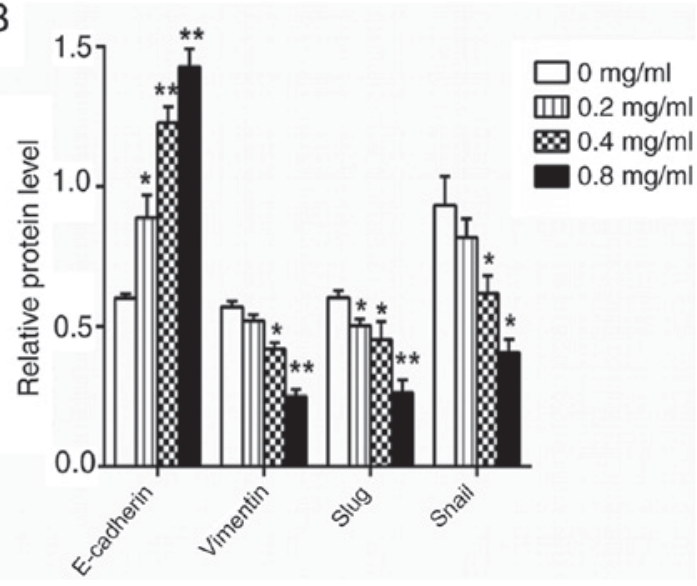

Figure 8. Matrine suppresses the levels of EMT-associated proteins in Huh-7 cells. (A) Huh-7 cells were treated with various concentrations of matrine $(0,0.2,0.4$ and $0.8 \mathrm{mg} / \mathrm{ml})$ and then subjected to a western blotting assay to estimate levels of EMT-associated proteins. (B) Measurement of the levels of EMT-associated proteins in Huh-7 cells. The data are presented as the mean \pm standard deviation of three independent experiments. ${ }^{*} \mathrm{P}<0.05$ and ${ }^{* *} \mathrm{P}<0.001$ vs. the $0 \mathrm{mg} / \mathrm{ml}$ matrine group. EMT, epithelial-mesenchymal transition; Snail, zinc-finger protein Snai1; Slug, zinc-finger protein Snai2; E, epithelial.
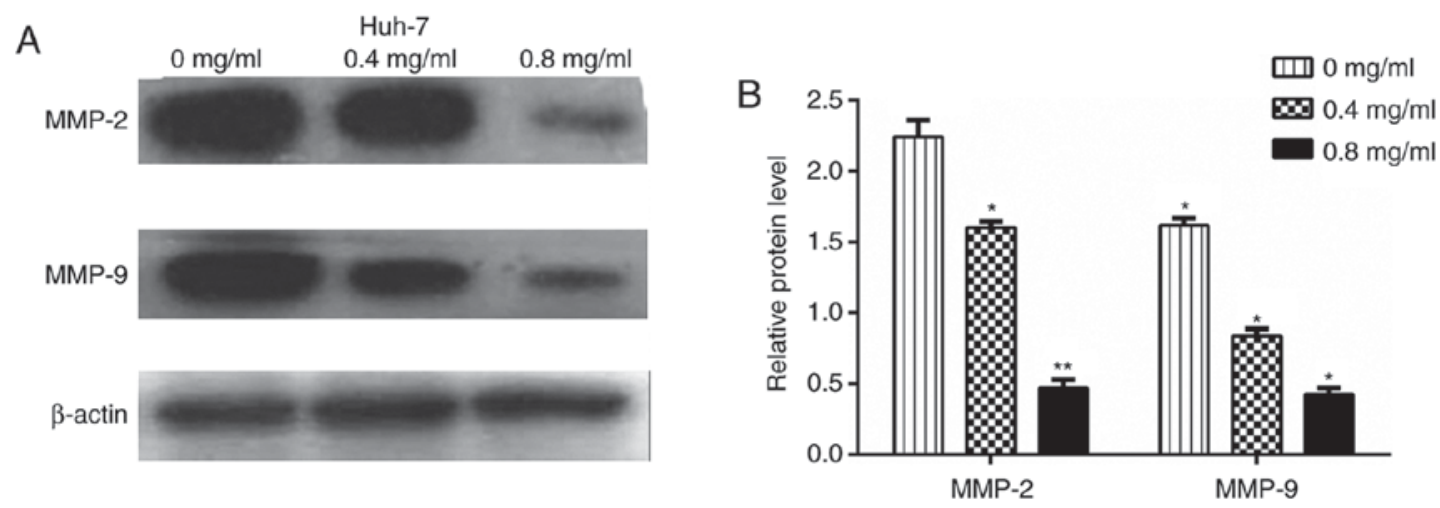

Figure 9. Effect of matrine on the MMP2 and MMP9 in Huh-7 cells. (A) Huh-7 cells were treated with various concentrations of matrine $(0,0.4 \mathrm{and} 0.8 \mathrm{mg} / \mathrm{ml})$ and then subjected to western blot analysis to assess the protein levels of MMP2 and MMP9. (B) Measurement of the protein levels of MMP2 and MMP9 in Huh-7 cells. The data are presented as the mean \pm standard deviation of three independent experiments. ${ }^{*} \mathrm{P}<0.05$ and ${ }^{* *} \mathrm{P}<0.01 \mathrm{vs}$. the $0 \mathrm{mg} / \mathrm{ml} \mathrm{matrine}$ group. MMP, matrix metalloproteinase.
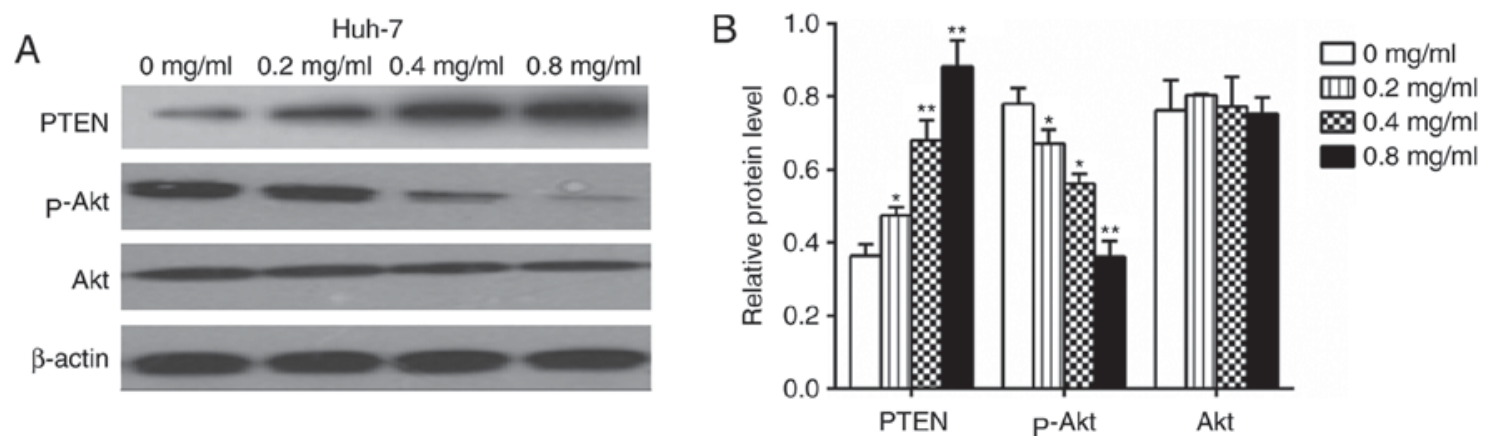

Figure 10. Effect of matrine on the PTEN/Akt pathway in Huh-7 cells. (A) Huh-7 cells were treated with various concentrations of matrine $(0,0.2,0.4$ and $0.8 \mathrm{mg} / \mathrm{ml}$ ) and then subjected to western blot analysis to assess the protein levels of PTEN, p-Akt, and Akt. (B) Measurement of the protein levels of PTEN, p-Akt and Akt in Huh-7 cells. The data are presented as the mean \pm standard deviation of three independent experiments. ${ }^{*} \mathrm{P}<0.05$ and ${ }^{* * *} \mathrm{P}<0.01$ vs. the $0 \mathrm{mg} / \mathrm{ml}$ matrine group. p-Akt, phosphorylated protein kinase B; PTEN, phosphatidylinositol 3,4,5-trisphosphate 3-phosphatase and dual-specificity protein phosphatase PTEN.

rates (20). Matrine has been confirmed as a natural anti-tumor agent against several types of cancer, including acute myeloid leukemia, prostate cancer, lung cancer and human hepatoma (21-24). Nevertheless, the anti-metastatic effect of matrine and its associated mechanism(s) in $\mathrm{HCC}$ remained unclear. In the present study, matrine was determined to inhibit the mobility and invasive capability of hepatoma cells in vitro by modulating EMT via the activation of the PTEN/Akt pathway. To the best of 
the authors' knowledge, this is the first scientific study to report the anti-metastatic effect of matrine on HCC.

In the present study, HCC cell line Huh-7 cells were treated with matrine at concentrations lower than $1 \mathrm{mg} / \mathrm{ml}$, which exerted minimal effects on cell proliferation as confirmed by an MTT assay. Notably, the cell morphology altered and a decrease in lamellipodia, focal adhesion, and the stress fibers in cells following treatment with matrine was observed. Based on this observation, EMT-associated markers were analyzed. As anticipated, the expression levels of mesenchymal markers were reduced and those of epithelial markers were upregulated in the matrine-treated cells. Transwell and wound healing assays were also used to analyze the invasive and migratory abilities of hepatoma cells; these properties were demonstrated to be suppressed. Therefore, these data indicated that matrine may inhibit HCC invasion and metastasis by inducing EMT, which is consistent with other studies that focused on different cancer types $(21,22)$.

Tumor metastasis and recurrence are two of the most difficult challenges in curing hepatoma patients. To fully progress to metastasis, carcinoma cells must complete multiple distinct steps. An important biological process that has been demonstrated to trigger cancer progression, metastasis and recurrence is EMT (25). Indeed, tumor metastasis has been associated with alterations in EMT markers (26), including decreased E-cadherin expression (27), increased MMPs expression (28) increased vimentin expression (29), increased collagen I expression (30), increased fibronectin expression (31) and increased expression of transcription factors from the Snail family (32). The phenomenon of EMT results in epithelial cells losing their cell-cell adhesions, acquiring a mesenchymal phenotype and also losing organized F-actin. This causes cells to become more migratory and invasive, and in the case of tumor cells, the ultimate consequence is metastatic spread (27). In the present study, it was observed that matrine enhanced E-cadherin expression and reduced the expression of vimentin, Slug, Snail, MMP2 and MMP9. The results suggested that the anti-metastatic effect of matrine on $\mathrm{HCC}$ is associated with EMT.

EMT refers to a series of phenotypic and molecular alterations that occur in non-cancerous cells over the course of various steps of normal development as well as in cancer cells (33). When EMT develops in cancer, the patient's prognosis may be adversely affected (34). Therefore, an important property of antineoplastic medicine is thought to be the successful repression of EMT $(35,36)$. Several phytochemicals, including matrine, may offer a novel therapeutic approach for treating tumors by repressing EMT (37-40). A previous study demonstrated that the phosphoinositide 3-kinase (PI3K)/Akt pathway serves a significant role in cell growth, metabolism, proliferation, migration and apoptosis (41). Furthermore, p-Akt is a well-known anti-apoptotic protein and the primary downstream kinase of PI3K (42). Accordingly, the p-Akt levels in HCC cells treated with matrine were investigated and the results demonstrated that the p-Akt expression levels were reduced in a concentration-dependent manner. To further clarify the mechanism involved, the upstream regulatory factors of Akt, including PTEN were measured. PTEN is tumor suppressor protein with protein phosphatase and alkaline phosphatase activity and that can inhibit the PI3K/Akt pathway (43). A previous study confirmed that the p-Akt, p27 and pS6 expression levels were increased in HCC tissues compared with the adjacent non-tumor and normal liver tissues and the normal tissue demonstrated elevated PTEN expression compared with the tumor tissue (44). Furthermore, this previous study demonstrated that over-expression of $\mathrm{p}$-Akt, p27 and pS6 was involved in poor differentiation, vascular invasion and high tumor node metastasis stage of HCC, all of which were also inversely proportional to PTEN expression. A previous study demonstrated that silencing PTEN inhibited the cell growth inhibition and apoptosis induced by matrine in M21 cells (45). These results suggested that PTEN was required for the antitumor efficacy of matrine. In addition, loss of PTEN function is the most commonly known genetic alteration in the PI3-kinase cascade and is commonly associated with B-Raf proto-oncogene mutations (45). Furthermore, in line with recent findings, their results revealed that HCC cells with downregulated p-Akt, p27 and pS6 expression exhibited decreased invasion and metastasis (46). In addition, the induction of EMT by transforming growth factor (TGF)- $\beta$ is implicated in hepatocarcinogenesis and HCC metastasis. These results demonstrated that upregulation of HAb18G/cluster of differentiation (CD)147 is stimulated by TGF- $\beta$ and is coupled with the downregulation of E-cadherin and the upregulation of neural-cadherin and vimentin. HAb18G/CD147 expression is controlled by the PI3K/Akt/phosphoinositide 3-kinase (GSK3b) cell survival signaling pathway and is directly regulated by the transcription factor Slug. One study revealed a novel effect of HAb18G/CD147 in mediating EMT during the course of HCC progression and demonstrated that CD147 is a Slug target in the TGF- $\beta$-PI3K/Akt-GSK3b-Snail-Slug-CD147 signaling cascade (47). Further experiments are required to confirm the association of the expression of the PTEN/p-Akt and the inhibitory effects of matrine. Therefore, the present study investigated these downstream EMT regulators of the PI3K/Akt pathway and reported that Snail and Slug expression was downregulated in matrine-treated HCC cells. The results demonstrated that the PTEN/PI3K/Akt pathway may serve as an alternative mechanism underlying the effects of matrine.

In conclusion, the present study confirmed the inhibitory function of matrine on the invasive and metastatic abilities of HCC. Furthermore, decreases in vimentin expression and increases in E-cadherin expression induced by matrine are attributed to enhanced PTEN activity and inhibited Akt signaling. This mechanism may contribute to the inhibitory effects of matrine on invasion and metastasis in HCC. These results also revealed a novel potential therapeutic application of matrine as an anti-metastatic therapy for HCC.

\section{Acknowledgements}

The authors would like to thank Dr Pan for his helpful advice regarding manuscript preparation. The present study was performed in the First Affiliated Hospital of Harbin Medical University Laboratory and the Shenzhen Longhua District Central Hospital Laboratory.

\section{Funding}

No funding was received. 


\section{Availability of data and materials}

All data generated or analyzed during this study are include in this published article.

\section{Authors' contributions}

YWW, BLC and SJZ conceived and designed the research study. YWW, SJZ, JL and BBF performed the experiments and data analysis described. YWW and JY prepared the figures and drafted the manuscript. YWW was a major contributor in writing the manuscript. All authors read and approved the final manuscript.

\section{Ethics approval and consent to participate}

Not applicable.

\section{Consent for publication}

Not applicable.

\section{Competing interests}

The authors declare they have no competing interests.

\section{References}

1. Berreta M, Rinaldi L, Di Benedetto F, Lleshi A, De Re V, Facchini G, De Paoli P and Di Francia R: Angiogenesis inhibitors for the treatment of hepatocellular carcinoma. Front Pharmacol 7: 428, 2016.

2. Germano D and Daniele B: Systemic therapy of hepatocellular carcinoma: Current status and future perspectives. World J Gastroenterol 20: 3087-3099, 2014.

3. Ingle PV, Samsudin SZ, Chan PQ, Ng MK, Heng LX, Yap SC, Chai AS and Wong AS: Development and novel therapeutics in hepatocellular carcinoma: A review. Ther Clin Risk Manag 12: 445-455, 2016.

4. Knox JJ, Qin R, Strosberg JR, Tan B, Kaubisch A El-Khoueiry AB, Bekaii-Saab TS, Rousey SR, Chen HX and Erlichman C: A phase II trial of bevacizumab plus temsirolimus in patients with advanced hepatocellular carcinoma. Invest New Drugs 33: 241-246, 2015.

5. Chaffer CL, San Juan BP, Lim E and Weinberg RA: EMT, cell plasticity and metastasis. Cancer Metastasis Rev 35: 645-654, 2016.

6. Zhou SL, Zhou ZJ, Hu ZQ, Li X, Huang XW, Wang Z, Fan J, Dai $Z$ and Zhou J: CXCR2/CXCL5 axis contributes to epithelial-mesenchymal transition of HCC cells through activating PI3K/Akt/GSK-3ß\snail signaling. Cancer Lett 358: 124-35, 2015.

7. Darroli AA, Hink MA, DuBuc TQ, Teunisse BJ, Goedhart J, Röttinger E and Postma M: Domain analysis of the nematostella vectensis snail ortholog reveals unique nucleolar localization that depends on the zinc-finger domains. Sci Rep 5: 12147, 2015.

8. Luo Z, Wang Q, Lau WB, Lau B, Xu L, Zhao L, Yang H, Feng M, Xuan Y, Yang Y, et al: Tumor microenvironment: The culprit for ovarian cancer metastasis? Cancer Lett 377: 174-182, 2016.

9. Chen CM, Hsieh SC, Lin CL, Lin YS, Tsal JP and Hsieh YH: Alpha-mangostin suppresses the metastasis of human renal carcinoma cells by targeting MEK/ERK expression and MMP9 transcription activity. Cell Physiol Biochem 44: 1460-1470, 2017.

10. Kean MJ, Williams KC, Skaiski M, Myers D, Burtnik A, Foster D and Coppolino MG: VAMP3, syntaxin-13 and SNAP23 are involved in secretion of matrix metalloproteinases, degradation of the extracellular matrix and cell invasion. J Cell Sci 122: 4089-4098, 2009
11. Horejs CM, Serio A, Purvis A, Gormley AJ, Bertazzo S, Poliniewicz A, Wang AJ, DiMaggio P, Hohenester E and Stevens MM: Biologically-active laminin-111 fragment that modulates the epithelial-to-mesenchymal transiton in embryonic stem cells. Proc Natl Acad Sci USA 111: 5908-5913, 2014

12. Niu $\mathrm{H}$, Zhang $\mathrm{Y}, \mathrm{Wu} \mathrm{B}$, Zhang $\mathrm{Y}$, Jiang $\mathrm{H}$ and $\mathrm{He} \mathrm{P}$ : Matrine induces the apoptosis of lung cancer cells through downregulation of inhibitor of apoptosis proteins and the Akt signaling pathway. Oncol Rep 32: 1087-1093, 2014.

13. Wang CY, Bai XY and Wang CH: Traditional Chinese medicine: A treasured natural resource of anticancer drug research and development. Am J Chin Med 42: 543-559, 2014.

14. Ou X, Chen Y, Cheng X, Zhang X and He Q: Potentiation of resveratrol-induced apoptosis by matrine in human hepatoma HepG2 cells. Oncol Rep 32: 2803-2809, 2014.

15. Ding Y, Li X, Hong D, Jiang L, He Y and Fang H: Slience of MACC1 decreases cell migration and invasion in human maliganant melanoma through inhibiting the EMT. Biosci Trends 10: 258-264, 2016.

16. Liu S, Ye D, Xu D, Liao Y, Zhang L, Liu L, Yu W, Wang Y, He Y, $\mathrm{Hu} \mathrm{J}$, et al: Autocrine epiregulin activates EGFR pathway for lung metastasis via EMT in salivary adenoid cystic carcinoma. Oncotarget 7: 25251-25263, 2016.

17. Beerling E, Seinstra D, de Wit E, Kester L, van der Velden D, Maynard C, Schäfer R, van Diest P, Voest E, van Oudenaarden A, et al: Plasticity between epithelial and mesenchymal states unlinks EMT from metastasis-enhancing stem cell capacity. Cell Rep 14: 2281-2288, 2016.

18. Goncalves Ndo N, Colombo J, Lopes JR, Gelaleti GB, Moschetta MG, Sonehara NM, Hellmén E, Zanon Cde F, Oliani SM and Zuccari DA: Effect of melatonin in epithelial mesenchymal transition markers and invasive properties of breast cancer stem cells of canine and human cell lines. PLoS One 11: e0150407, 2016

19. Lin SY, Lee YX, Yu SL, Chang GC and Chen JJ: Phosphatase of regenerating liver-3 inhibits invasiveness and proliferation in non-small cell lung cancer by regulating the epithelial-mesenchymal transition. Oncotarget 7: 21799-21811, 2016.

20. Reig M, Mariño Z, Perelló C, Iñarrairaegui M, Ribeiro A, Lens S, Díaz A, Vilana R, Darnell A, Varela M, et al: High rate of early tumor recurrence in patients with HCV-related HCC undergoing interferon-free therapy. J Hepatol 65: 719-726, 2016.

21. Wu J, Hu G, Dong Y, Ma R, Yu Z, Jiang S, Han Y, Yu K and Zhang S: Matrine induces Akt/mTOR signalling inhibition-mediated autophagy and apoptosis in acute myeloid leukaemia cells. J Cell Mol Med 21: 1171-1181, 2017.

22. Huang H, Du T, Xu G, Lai Y, Fan X, Chen X, Li W, Yue F, Li Q, Liu L and Li K: Matrine suppresses invasion of castration-resistant prostate cancer cells by downregulating MMP-2/9 via NF-אM signaling pathway. Int J Oncol 50: 640-648, 2017.

23. Wu L, Wang G, Liu S, Wei J, Zhang S, Li M, Zhou G and Wang L: Synthesis and biological evaluation of matrine derivatives containing benzo-enpyrone structure as potent anti-lung cancer agents. Sci Rep 6: 35918, 2016.

24. Liu Y, Qi Y, Bai ZH, Ni CX, Ren QH, Xu WH, Xu J, Hu HG, Qiu L, Li JZ, et al: A novel matrine derivate inhibits differentiated human hepatoma cells and hepatic cancer stem-like cells by suppressing PI3K/AKT signaling pathways. Acta Pharmacol Sin 38: 120-132, 2017.

25. Sato R, Semba T, Saya H and Arima Y: Concise review: Stem cells and epithelial-mesenchymal transition in cancer: Biological implications and therapeutic targets. Stem Cells 34: 1997-2007, 2016.

26. Bronsert P, Enderle-Ammour K, Bader M, Timme S, Kuehs M, Csanadi A, Kayser G, Kohler I, Bausch D, Hoeppner J, et al: Cancer cell invasion and EMT marker expression: A three-dimensional study of the human cancer-host interface. J Pathol 234: 410-422, 2014.

27. Canesin G, Cuevas EP, Santos V, López-Menéndez C, MorenoBueno G, Huang Y, Csiszar K, Portillo F, Peinado H, Lyden D and Cano A: Lysyl oxidase-like 2 (LOXL2) and E47 EMT factor: Novel partners in E-cadherin repression and early metastasis colonization. Oncogene 34: 951-964, 2015.

28. Qu M, Yu J, Liu H, Ren Y, Ma C, Bu X and Lan Q: The candidate tumor suppressor gene SLC8A2 inhibits invasion, angiogenesis and growth of glioblastoma. Mol Cells 40: 761-772, 2017.

29. Zhang J, Liu D, Feng Z, Mao J, Zhang C, Lu Y, Li J, Zhang Q, $\mathrm{Li} \mathrm{Q}$ and Li L: MicroRNA-138 modulates metastasis and EMT in breast cancer cells by targeting vimentin. Biomed Pharmacother 77: 135-141, 2016. 
30. Islam SS, Mokhtari RB, El Hout Y, Azadi MA, Alauddin M, Yeger $\mathrm{H}$ and Farhat WA: TGF- $\beta 1$ induces EMT reprogramming of porcine bladder urothelial cells into collagen producing fibroblasts-like cells in a Smad2/Smad3-dependent manner. J Cell Commun Signal 8: 39-58, 2014.

31. Wu YM, Chen ZJ, Liu H, Wei WD, Lu LL, Yang XL, Liang WT, Liu T, Liu HL, Du J and Wang HS: Inhibition of ERR $\alpha$ suppresses epithelial mesenchymal transition of triple negative breast cancer cells by directly targeting fibronectin. Oncotarget 6: 25588-25601, 2015.

32. Jin Y, Shenoy AK, Doernberg S, Chen H, Luo H, Shen H, Lin T, Tarrash M, Cai Q, Hu X, et al: FBXO11 promotes ubiquitination of the Snail family of transcription factors in cancer progression and epidermal development. Cancer Lett 362: 70-82. 2015.

33. Verdone JE, Parsana P, Veltri RW and Pienta KJ: Epithelialmesenchymal transition in prostate cancer is associated with quantifiable changes in nuclear structure. Prostate 75: 218-224, 2015.

34. Colangelo T, Fucci A, Votino C, Sabatino L, Pancione M, Laudanna C, Binaschi M, Bigioni M, Maggi CA, Parente D, et al: MicroRNA-130b promotes tumor development and is associated with poor prognosis in colorectal cancer. Neoplasia 15: 1086-1099, 2013

35. Lv XQ, Qiao XR, Su L and Chen SZ: Honokiol inhibits EMT-mediated motility and migration of human non-small cel lung cancer cells in vitro by targeting c-FLIP. Acta Pharmacol Sin 37: 1574-1586, 2016.

36. Tong D, Liu Q, Liu G, Xu J, Lan W, Jiang Y, Xiao H, Zhang D and Jiang J: Metformin inhibits castration-induced EMT in prostate cancer by repressing COX2/PGE2/STAT3 axis. Cancer Lett 389: 23-32, 2016.

37. Kim EK, Choi EJ and Debnath T: Role of phytochemicals in the inhibition of epithelial-mesenchymal transition in cancer metastasis. Food Funct 7: 3677-3685, 2016.

38. Kallifatidis G, Hoy JJ and Lokeshwar BL: Bioactive natural products for chemoprevention and treatment of castration-resistant prostate cancer. Semin Cancer Biol 40-41: 160-169, 2016.

39. Murden K, San KK, Martino A and Ezekiel U: The effect of phytochemicals on a chemoresistant, epithelial-mesenchymal transitioned, colorectal cancer cell line. FASEB J 30: 1090.2, 2016.
40. Wang Z, Wu Y, Wang Y, Jin Y, Ma X, Zhang Y and Ren H: Matrine inhibits the invasive properties of human glioma cells by regulating epithelial-to-mesenchymal transition. Mol Med Rep 11: 3682-3686, 2015.

41. Lim W, Yang C, Bazer FW and Song G: Luteolin inhibits proliferation and induces apoptosis of human placental choriocarcinoma cells by blocking the PI3K/AKT pathway and regulating sterol regulatory element binding protein activity. Biol Reprod 95: 82, 2016.

42. Winnay JN, Solheim MH, Dirice E, Sakaguchi M, Noh HL, Kang HJ, Takahashi H, Chudasama KK, Kim JK, Molven A, et al: PI3-kinase mutation linked to insulin and growth factor resistance in vivo. J Clin Invest 126: 1401-1412, 2016.

43. Jing X, Cheng W, Wang S, Li P and He L: Resveratrol induces cell cycle arrest in human gastric cancer MGC803 cells via the PTEN-regulated PI3K/Akt signaling pathway. Oncol Rep 35: 472-478, 2016.

44. Su R, Nan H, Guo H, Ruan Z, Jiang L, Song Y and Nan K: Associations of components of PTEN/AKT/mTOR pathway with cancer stem cell markers and prognostic value of these biomarkers in hepatocellular carcinoma. Hepatol Res 46: 1380-1391, 2016.

45. Jin H, Sun Y, Wang S and Cheng X: Matrine activates PTEN to induce growth inhibition and apoptosis in V600EBRAF harboring melanoma cells. Int J Mol Sci 14: 16040-16057, 2013.

46. Du R, Liu Z, Hou X, Fu G, An N and Wang L: Trichostatin A potentiates genistein-induced apoptosis and reverses EMT in HEp2 cells. Mol Med Rep 13: 5045-5052, 2016.

47. Ru NY, Wu J, Chen ZN and Bian H: HAb18b18G/CD147 is involved in TGF- $\beta$-induced epithelial-mesenchymal transition and hepatocellular carcinoma invasion. Cell Biol Int 39: 44-51, 2015.

This work is licensed under a Creative Commons Attribution-NonCommercial-NoDerivatives 4.0 International (CC BY-NC-ND 4.0) License. 